\title{
Influence of substrate material on the life of atmospheric plasmas prayed thermal barrier coatings
}

Robert Eriksson, Sten Johansson, Håkan Brodin, Esteban Broitman, Lars Östergren and XinHai Li

\section{Linköping University Post Print}

\section{Tweet}

N.B.: When citing this work, cite the original article.

Original Publication:

Robert Eriksson, Sten Johansson, Håkan Brodin, Esteban Broitman, Lars Östergren and XinHai Li, Influence of substrate material on the life of atmospheric plasmas prayed thermal barrier coatings, 2013, Surface \& Coatings Technology, (232), 15, 795-803.

http://dx.doi.org/10.1016/j.surfcoat.2013.06.101

Copyright: Elsevier

http://www.elsevier.com/

Postprint available at: Linköping University Electronic Press

http://urn.kb.se/resolve?urn=urn:nbn:se:liu:diva-96810 


\title{
Influence of Substrate Material on the Life of Atmospheric Plasma Sprayed Thermal Barrier Coatings
}

\author{
Robert Eriksson ${ }^{\mathrm{a}, *}$, Sten Johansson ${ }^{\mathrm{a}}$, Håkan Brodin ${ }^{\mathrm{b}, \mathrm{a}}$, Esteban Broitman ${ }^{\mathrm{c}}$, \\ Lars Östergren ${ }^{\mathrm{d}}$, Xin-Hai Li ${ }^{\mathrm{b}}$ \\ ${ }^{a}$ Division of Engineering Materials, Department of Management and Engineering, \\ Linköping University, SE-58183 Linköping, Sweden \\ ${ }^{b}$ Siemens Industrial Turbomachinery AB, SE-61283 Finspong, Sweden \\ ${ }^{c}$ Department of Physics, Chemistry and Biology, Linköping University, SE-58183 \\ Linköping, Sweden \\ ${ }^{d}$ GKN Aerospace Engine Systems, SE-46181 Trollhättan, Sweden
}

\begin{abstract}
Thermal barrier coatings (TBCs) are used in gas turbines to prolong the life of the underlying substrates and to increase the efficiency of the turbines by enabling higher combustion temperatures. TBCs may fail during service due to thermal fatigue or through the formation of non-protective thermally grown oxides (TGOs). This study compares two atmospheric plasma sprayed (APS) TBC systems comprising of two identical TBCs deposited on two different substrates (Haynes 230 and Hastelloy X). The thermal fatigue life was found to differ between the two TBC systems. The interdiffusion of substrate elements into the coating was more pronounced in the TBC system with shorter life, however, very few of the substrate elements (only Mn and to some extent Fe) formed oxides in the bond coat/top coat interface. Fractography revealed no differences in the fracture behaviour of the TBCs; the fracture occurred, in both cases, to about $60 \%$ in the top coat close to the interface and the remainder in the interface. Nanoindentation revealed only small differences in mechanical properties between the TBC systems and a finite element crack growth analysis showed that such small differences did not cause any significant change in the crack driving force. The oxidation kinetics was found to be similar for both TBC systems for the formation
\end{abstract}

\footnotetext{
*Corresponding author. Tel.: +46 13 284410; fax: +46 13 282505. E-mail address: robert.eriksson@liu.se
} 
of $\mathrm{Al}_{2} \mathrm{O}_{3}$ but differed for the kinetics of non- $\mathrm{Al}_{2} \mathrm{O}_{3}$ TGOs where the TBC system with shortest life had a faster formation of non- $\mathrm{Al}_{2} \mathrm{O}_{3}$ TGOs caused by a faster $\mathrm{Al}$ depletion. The difference in non- $\mathrm{Al}_{2} \mathrm{O}_{3} \mathrm{TGO}$ growth kinetics was considered to be the main reason for the difference in life.

Keywords: thermal barrier coating, TBC, substrate influence, interdiffusion, fatigue life, oxidation kinetics

\section{Introduction}

Gas turbines operate at temperatures where phenomena such as oxidation and creep occur readily. Thermal barrier coating (TBC) systems have become common in gas turbines as they lower the temperature of the underlying substrate and provide protection against high-temperature degradation of the substrate materials [1]. TBC systems thus prolong the life of structural parts, as well as increase the gas turbine efficiency by enabling higher combustion temperatures [2-5].

TBCs consist of a metallic bond coat (BC) and a ceramic top coat (TC) deposited on the substrate by methods such as atmospheric plasma spray (APS), electron beam physical vapour deposition (EB-PVD) and high velocity oxy-fuel (HVOF) spray $[1,3,6]$. The APS process gives rise to a typical splat-on-splat microstructure. The contact between layers of splats may be quite low, and there consequently exists delaminations between the splats which, in the TC, may act as crack paths [7].

The bond coat is often chosen from the MCrAlX family of alloys where $\mathrm{M}$ is $\mathrm{Ni}$ and/or Co and $\mathrm{X}$ is any combination of reactive elements that improve oxidation resistance, typically $\mathrm{Y}$ but also, for example, Ta and $\mathrm{Si}[4,5]$. The bond coat provides oxidation resistance through the formation of alumina [8] and also provides sufficient adhesion of the APS top coat. The top coat is made of yttria partially stabilised zirconia (Y-PSZ) and provides the desired thermal insulation.

When used in gas turbines, the TBC systems are subjected to changes in temperature. Several experimental setups exist to test the durability of TBCs during such temperature cycling, for example the thermal cycling fatigue (TCF) rig and the burner rig $[9,10]$. As the TBC system is thermally cycled, the difference in coefficient of thermal expansion (CTE) between the metal and ceramic components in the TBC system causes stresses in the coating interface regions $[11,12]$ and the TBC system eventually fails by fatigue. 
Failure occurs by spallation of the top coat, and the TBC system thus loses its insulating capability.

Another mechanism of TBC failure is through the formation of thermally grown oxides (TGOs) in the $\mathrm{BC} / \mathrm{TC}$ interface [13]. When the aluminium reservoir in the bond coat is depleted, through oxidation and interdiffusion, voluminous non-protective oxides, such as chromia, mixed-element spinels and $\mathrm{NiO}$, may form. Voluminous non-protective oxides may introduce cracking due to growth stresses, thereby causing failure of the TBC $[8,14]$.

It has been shown, mainly for EB-PVD TBCs, that the life of TBC systems depends on the substrate on which the TBC is deposited [15-20]. For EB-PVD TBCs, a few possible mechanisms for the observed difference in life have been suggested. For failure occurring mainly in the BC/TGO interface, it has been suggested that the substrate may influence the BC/TGO interface toughness $[15,16]$. Characteristics of the substrate that have been found to decrease TBC life include $[17,18]$ : substrates high in refractory elements; substrates low in C, B and Cr; substrates with a larger CTE mismatch with the BC. Furthermore, substrates with more Kirkendall porosity at the substrate/BC interface, i.e. more pronounced interdiffusion, have been reported to have shorter life [18]. While a shorter TBC life, for some substrates, cannot necessarily be explained by faster oxidation kinetics $[17,18]$, it has also been shown that the substrate may influence the morphology of the TGO and the $\mathrm{BC} / \mathrm{TGO}$ interface where uneven TGO with pegs protruding into the $\mathrm{BC}$ gave longer life [18]. Mechanisms that have been suggested to promote longer TBC life include [17, 19]: addition of Hf may form beneficial Hf-rich pegs in the interface; de-sulphurised substrates may promote longer life; Y additions to sulphur-containing substrates may be beneficial. It has also been shown that low creep strength of the bond coat/substrate may be beneficial for TBC life [21].

While it is obvious that the substrate material influences the thermal fatigue life of TBCs, the governing mechanisms are still not fully understood and further research is necessary. So far, attention has mainly been given to turbine blade materials and EB-PVD TBCs. The effect of substrate material on the life of APS TBCs on typical combustor materials is still unexplored. Therefore, the influence of two wrought combustor materials on the thermal fatigue life of air plasma sprayed TBCs has been studied. The present study involves thermal cycling of two TBC systems typically used in gas turbine combustors: APS TBCs on Hastelloy X and Haynes 230. The current paper presents a study of the influence of substrate material on oxidation kinetics, 
interdiffusion and mechanical properties of the bond coat.

\section{Experimental}

\subsection{Material}

Two TBC systems with different substrate materials were studied. The substrates were cut from bars, $25 \mathrm{~mm}$ and $32 \mathrm{~mm}$ in diameter, to give discshaped specimens, $5 \mathrm{~mm}$ in thickness, which were grit blasted and deposited on one side with a $170 \mu \mathrm{m}$ APS bond coat and a $1500 \mu \mathrm{m}$ APS top coat using a Sulzer MetcoTriplex gun. The coating deposition was made by GKN Aerospace Engine Systems, Trollhättan, Sweden. The two substrate materials used were Hastelloy X (Ni-22Cr-18Fe-9Mo-0.6W-0.5Mn, wt.\%, with minor additions of Co and C) and Haynes 230 (Ni-22Cr-14W-1.5Fe-1.3Mo$0.6 \mathrm{Mn}-0.3 \mathrm{Al}$, wt.\%, with minor additions of $\mathrm{Co}$ and $\mathrm{C}$ ). The bond coat used was a Ni-12Co-20Cr-12Al with minor additions of Y, Si and Ta, and the top coat was made from $7 \%$ partially-stabilised zirconia. The two TBC systems will be referred to as HX for TBC on Hastelloy X, and H230 for TBC on Haynes 230.

\subsection{High-temperature exposure}

The $32 \mathrm{~mm}$ diameter specimens were used for thermal cycling fatigue which involved $1 \mathrm{~h}$ at $1100{ }^{\circ} \mathrm{C}$ followed by $10 \mathrm{~min}$ of cooling by compressed air, resulting in a minimum temperature of $100{ }^{\circ} \mathrm{C}$. Thermal cycling was typically performed until failure of the TBC which was defined as $\sim 20 \%$ visible delamination of the TBC. When removed from the furnace, and allowed to cool to room temperature, the top coat typically spalled off completely in one piece. Two specimens of each TBC system was used for TCF.

The $25 \mathrm{~mm}$ diameter specimens were used for isothermal oxidation at $1100{ }^{\circ} \mathrm{C}$ for times up to $1650 \mathrm{~h}$. Specimens were removed from the furnace at $100 \mathrm{~h}, 300 \mathrm{~h}, 500 \mathrm{~h}, 1000 \mathrm{~h}$ and $1650 \mathrm{~h}$. The test was aborted when the top coat spalled on cooling after being removed from the furnace which happen at $1000-1650 \mathrm{~h}$.

\subsection{Specimen preparation and microscopy}

The fracture surfaces, resulting from the thermal cycling test, were analysed in a FEG-SEM Hitachi SU-70 scanning electron microscope (SEM) 
equipped with an energy dispersive spectroscopy (EDS) detector from $O x$ ford Instruments. EDS was performed on the fracture surfaces to establish the oxide composition; measurements at 20-30 different locations on the fracture surface was usually enough to give a good mean value. The isothermally oxidised specimens were infiltrated in epoxy in vacuum, crosssectioned, mounted and polished for microscopy. EDS was performed on the cross-sectioned specimens along a $\sim 800 \mu \mathrm{m}$ long line through the thickness of the coating continuing into the substrate, to establish the composition change due to interdiffusion. The obtained oxygen concentration was used to identify and remove internal oxides from the obtained concentration profiles since only the metallic composition was of interest. The cross-sectioned specimens were also used to establish the TGO thickness which was measured at 100 equidistant points along the length of the interface.

\subsection{Mechanical properties}

The Young's moduli of the coating and the substrate were established with nanoindentation at room temperature. The nanoindentation tests were performed using a TI-950 Triboindenter from Hysitron, Inc., Minneapolis. The nanoindenter was equipped with a Berkovich $142.3^{\circ}$ diamond-probe with a tip radius of $\sim 150 \mathrm{~nm}$. The maximum load used was $1 \mathrm{mN}$. For each specimen, 8-12 indents were made in the metallic parts of the coating and 8-12 indents in the substrate about $200 \mu \mathrm{m}$ below the coating-substrate interface.

\section{Results}

\subsection{TCF life and fractography}

During TCF, the first HX specimen failed at 565 cycles; at the same time, a H230 specimen was removed from the furnace for comparison, it showed no signs of delamination at that time. The second HX specimen failed at 637 cycles and the remaining H230 specimen failed at 1070 cycles. The mean life of the HX hence becomes $\sim 600 \pm 40$ cycles. Based on previous experience, a \pm 50 scatter in life may be expected for these specimens and the life of the H230 specimen is considered to be $1070 \pm 50$. Thus, the H230 specimen almost had a factor 2 longer life than the HX specimen.

Fig. 1 shows an image from a typical fracture surface. The fracture occurred partly in the TGO/TC interface and partly in the TC; here referred to as dark and bright fracture respectively due to their appearance in a light 
optic microscope. The fracture occurred largely in pre-existing interfaces interfaces exists between the TGO and the TC, as well as between the splats that make up the TC - as oppose to in the bulk of the TGO or the TC splats.

The macroscopic appearance of the fracture surfaces for the $\mathrm{BC}$ - and TC-sides is shown in Fig. 2 a) and b), and the measured fractions of dark fracture are presented in Fig. 2 c). Interestingly, both coatings failed at roughly the same fraction of dark fracture, $\sim 40 \%$, even though the H230 specimen had been almost twice as long in the furnace. The dark fracture on the TC side of the fracture surface is mainly made up of bulky oxide clusters that protruded into the top coat and were cut through during cycling. The dark areas on the TC side are consequently mainly oxides such as chromia, spinels and $\mathrm{NiO}$. From comparing the fraction dark fracture on the BC- and TC-sides it can be concluded that the final fracture, on average, occurred to $60 \%$ in the TC, $6 \%$ in the TGO and $34 \%$ in the TGO/TC interface for both the HX and H230 specimens.

\subsection{Oxidation and interdiffusion}

Isothermal oxidation was aborted when the top coat spalled on cooling to room temperature after being removed from the furnace. The HX specimens remained intact up to $500 \mathrm{~h}$, but failed when removed from the furnace at $1000 \mathrm{~h}$. The H230 specimens remained intact up to $1000 \mathrm{~h}$, but failed when removed at $1650 \mathrm{~h}$. Cross-sections of the isothermally oxidised specimens are shown in Fig 3. As evident from the micrographs, which show the bond coats of the $\mathrm{HX}$ and $\mathrm{H} 230$ specimens after $500 \mathrm{~h}$ at $1100{ }^{\circ} \mathrm{C}$, there was a lot of internal oxidation in the bond coat for both the HX and the H230 specimens; the degree of internal oxidation was similar for both specimens. At the $\mathrm{BC} / \mathrm{TC}$ interface, a continuous oxide scale of predominantly $\mathrm{Al}_{2} \mathrm{O}_{3}$ formed, locally broken by bulky oxide cluster containing chromia, mixedelement spinels and $\mathrm{NiO}$; the $\mathrm{Al}_{2} \mathrm{O}_{3}$ scale, locally, also had an outer layer of Cr-rich oxides. With time $(\geq 500 \mathrm{~h})$ Si oxides and Ta-rich oxides formed, usually adjacent to the $\mathrm{Al}_{2} \mathrm{O}_{3}$ scale.

Fig. 4 shows the composition of the oxides on the fracture surfaces measured by EDS. The surface oxides have been divided into categories depending on their morphology: 1) continuous layer of essentially pure alumina, 2) blocky oxides, appear brighter in SEM backscatter mode and is blocky in morphology, 3) granular bright oxides (backscatter) often as a layer on top of the alumina. The latter two are shown in Fig. 5 and contain a mix of $\mathrm{Al}$, $\mathrm{Cr}$, Co and Ni from the coating and Mn and minor Fe from the substrate. 
As shown in Fig. 4, the H230 specimen oxidised 1070 cycles contains larger amounts of Mn. The incorporation of Mn into the oxides most likely occur by the formation of $\mathrm{Mn}_{1.5} \mathrm{Cr}_{1.5} \mathrm{O}_{4}$ spinels. In addition to $\mathrm{Mn}$, Fe from the substrate was found in small amounts in the TGOs, in the blocky and granular oxides, whereas the refractory elements, $\mathrm{W}$ and Mo, were not present in the TGO, except for very small amounts in the alumina.

Fig. 6 shows the elemental profiles obtained from cross-sectioned TBCs oxidised isothermally 500 and $1000 \mathrm{~h}$. The graphs show the composition change along a line from the $\mathrm{BC} / \mathrm{TC}$ interface, through the thickness of the bond coat and extending into the substrate, where negative distance is in the coating. At the time of failure, considerable interdiffusion had occurred, particularly for the HX specimens. After $500 \mathrm{~h}$ of high temperature exposure, which roughly corresponds to the time of failure for HX, the substrate elements found in the coating just beneath the TGO were 5.8 wt.\% Fe, 2.2 wt. $\%$ Mo and 0.3 wt. $\%$ Mn for HX and 0.5 wt. $\%$ Fe, 0.3 wt. $\%$ Mo, 0.4 wt. $\%$ $\mathrm{Mn}$ and 0.7 wt.\% $\mathrm{W}$ for $\mathrm{H} 230$. The $\mathrm{Al}$ content in the coating, just below the TGO, was higher for the H230 specimen: 0.3 wt.\% compared to 0.1 wt.\% for HX. More importantly, as can be seen in Fig. 6 c) and d), at 500 h the $\mathrm{H} 230$ specimen still had an $\mathrm{Al}$ reservoir in the coating centre while the $\mathrm{Al}$ in the HX specimen was essentially depleted. After $1000 \mathrm{~h}$ of high temperature exposure, which roughly corresponds to the time of failure for H230, the substrate elements found in the coating just beneath the TGO was 10.8 wt. $\%$ Fe, 5.3 wt. $\%$ Mo and 0.3 wt.\% Mn for HX and 0.9 wt.\% Fe, 0.8 wt.\% Mo, 0.4 wt.\% Mn and 3.3 wt.\% W for H230. After $1000 \mathrm{~h}$, the Al content beneath the TGO had dropped to about 0.2 wt.\% for the H230 specimen and, as evident from Fig. 6 e), the $\mathrm{Al}$ reservoir was depleted; the overall $\mathrm{Al}$ content in the coating was essentially the same as in the substrate.

Fig. 7 shows the parabolic oxidation curves derived from the experimental data: $h=\sqrt{k_{p} t}$ where $h$ is the interface TGO thickness, $k_{p}$ the oxide growth constant and $t$ is time. The figure shows the oxidation rate both for $\mathrm{Al}_{2} \mathrm{O}_{3}$ and the total thickness of the TGO which, in addition to alumina, also includes oxides such as chromia, mixed-element-spinels and nickel oxide. Comparing the oxidation rates of the two coating systems reveals that while the rate of alumina growth was very similar for the HX and H230 specimens, the total thickness of the TGO was greater for the HX specimen. At the time of failure, the TGO thickness for $\mathrm{HX}$ was $4.4 \mu \mathrm{m} \mathrm{Al}_{2} \mathrm{O}_{3}$ and $16.5 \mu \mathrm{m}$ total thickness, and for $\mathrm{H} 2307.0 \mu \mathrm{m} \mathrm{Al} \mathrm{O}_{3}$ and $14.4 \mu \mathrm{m}$ total thickness. Consequently, the specimens both failed at roughly the same total TGO thickness. 


\subsection{Mechanical properties of the bond coat}

Nanoindentation was performed to establish the mechanical properties of the bond coat and substrate after interdiffusion. The Young's modulus, E, was calculated according to

$$
E=\frac{1-\nu_{s}^{2}}{\frac{1}{E_{r}}-\frac{1-\nu_{i}^{2}}{E_{i}}}
$$

where $E_{r}$ is the measured reduced elastic modulus and $E_{i}=1140 \mathrm{GPa}$ and $\nu_{i}=0.07$ are the Young's modulus and Poisson's ratio respectively for the diamond indenter. Values of the specimen's Poisson's ratio, $\nu_{s}$ were taken from the literature [22] and were set to 0.29 for the substrate and 0.31 for the bond coat.

Fig. 8 shows the Young's moduli in the substrate and the bond coat. For the HX specimen, the modulus was constant with time and $\sim 235 \mathrm{GPa}$ for both coating and substrate. The modulus for H230 increased somewhat with time in both substrate and coating from $\sim 230 \mathrm{GPa}$ to $\sim 270 \mathrm{GPa}$.

\section{Discussion}

\subsection{Oxidation and interdiffusion}

Since the failure of the TBCs occurred to such a large extent in the TC, previously suggested mechanisms for substrate influence on life - previous work has mainly focused on the BC/TGO interface [15-19] - may not sufficiently explain the difference in life for the specimens studied here.

From the EDS measurements in cross-sections, it is clear that the bond coat on the HX specimen experiences a bigger change in chemistry compared to the H230 specimen: the total amount of substrate elements found beneath the TGO is 8.3 wt.\% for HX and 1.9 wt.\% for $\mathrm{H} 230$ after $500 \mathrm{~h}$ and the corresponding figures for $1000 \mathrm{~h}$ are $16.4 \mathrm{wt} . \%$ and $5.4 \mathrm{wt. \%}$. Other researchers $[17,18]$ have pointed out the possible negative effect of refractory elements in the substrate on the life of the coating; the Mo in the HX specimen do interdiffuse more readily than the $\mathrm{W}$ in the $\mathrm{H} 230$ specimen, however, the higher amount of substrate elements in the coating of the HX specimen is mainly due to interdiffusion of Fe. Furthermore, Al depletion occurs markedly faster

in the HX specimens. It is evident from Fig. 6 that, at the time of failure of the HX specimen, the H230 specimen still has an, albeit small, Al reservoir. 
At the time of failure of the H230 specimen, it too has been essentially depleted of Al. The possible effect of diffusion blocking in the substrate/bond coat interface should also be mentioned [23], see Fig. 3. However, since the pre-deposition grit blasting and the bond coat composition are identical for the two TBC systems, the difference in interdiffusion is unlikely to be caused by differences in the interfaces diffusion blocking.

The faster Al depletion in the HX specimen is also likely the reason for the faster formation of oxides other than alumina. Except for $\mathrm{Mn}$, and to some extent $\mathrm{Fe}$, very low amounts, if any, of the substrate elements were found in the TGO on the fracture surfaces; it is therefore concluded that the total TGO oxidation kinetics for the HX specimen was not accelerated by any of the substrate elements, but rather by the faster depletion of $\mathrm{Al}$.

The similar kinetics of $\mathrm{Al}_{2} \mathrm{O}_{3}$ formation for the $\mathrm{HX}$ and $\mathrm{H} 230$ specimens agrees with earlier observations $[17,18]$ and cannot explain the difference in life. This stresses the importance of also including non-alumina oxides in the TGO thickness measurements when oxidation kinetics is to be established. Many researchers have pointed out the role of TGO growth in limiting the TBC life $[8,14,24]$; the concept of a critical TGO thickness can even be used as a life prediction model of TBCs. Here, the specimens were observed to fail at similar TGO thickness, $16.5 \mu \mathrm{m}$ for HX and $14.4 \mu \mathrm{m}$ for H230, provided that the TGO thickness measurements included all formed TGOs.

Since Mn appears to readily form oxides in the BC/TC interface, preferably in the form of Mn-Cr-spinels, substrate materials high in Mn may have large influence on the life of TBCs. Here, the studied substrate alloy both had a Mn content of $\sim 0.5 \mathrm{wt} . \%$, and still locally large amounts of $\mathrm{Mn}$ in the TGO could be detected. The degree of Mn interdiffusion and Mn-Cr-oxide formation was similar for the two TBC systems. The Mn-Cr-oxides appear to have formed by incorporation of $\mathrm{Mn}$ in the $\mathrm{Cr}_{2} \mathrm{O}_{3}$.

\subsection{Crack growth modelling}

Crack growth modelling by the finite element (FE) software Abaqus was performed to investigate whether the crack driving force may be different for the different specimens. The two main sources of stress in the BC/TC interface during thermal cycling are: 1) stress due to the mismatch in CTE which is introduced during cooling and 2) growth stresses from the TGO. The crack growth FE modelling presented here will only include the former of the stress sources as has been done by several researches [11, 25, 26]. 
The possible difference in crack driving forces between the specimens will hence arise from differences in Young's modulus and CTE. At $500 \mathrm{~h}$ of oxidation, there is essentially no difference in Young's modulus between the specimens, but at $1000 \mathrm{~h}$ of high-temperature exposure the Young's modulus of the H230 specimen had increased somewhat compared to the HX specimen's modulus.

The CTE was estimated by the Thermo-Calc software. Data from the elemental profiles, Fig. 6, were used as input to estimate the variation in CTE through the thickness of the coating and the outermost part of the substrate; the results are shown in Fig. 9. The results from Thermo-Calc are thought to capture the main trend in the CTE variation, but the absolute values obtained may not be reliable enough. Therefore the calculated CTEs were adjusted (scaled) to agree with literature data of the substrates' CTEs. The CTEs derived this way are estimations, but are considered sufficient for the FE modelling performed here which aims at studying the influence of small changes in Young's modulus and CTE on the crack driving force.

The CTEs, at $500 \mathrm{~h}$ of high-temperature exposure, can be seen to be fairly similar for the H230 and HX specimens. At $1000 \mathrm{~h}$ of high-temperature exposure, the HX CTE starts approaching the CTE of the substrate as the interdiffusion in this specimen is quite pronounced at this time, as also seen in the composition profiles in Fig. 6. Because of the pronounced interdiffusion for the HX specimen at $1000 \mathrm{~h}$ of high-temperature exposure, it is motivated to model that coating with a somewhat larger thickness then the others; based on Fig. 6 and 9, the BC thickness was modelled $50 \%$ thicker for that specimen. Table 1 summarises the input data into the FE model; in addition to the Young's modulus and CTE values established here, literature data has been used from Jinnestrand [22].

A crack was modelled to run along the TGO/TC interface. The interface was modelled as a cosine wave, with an amplitude of $15 \mu \mathrm{m}$ and a wavelength of $100 \mu \mathrm{m}$, and the crack was assumed to grow from the peak position towards the valley position as previously done by others [11, 25, 26]; Fig. 10 illustrates this. It may be argued that a crack growing in this way will grow in a mixed mode [26] and, consequently, the stress intensity factors for both mode I and II, $K_{I}$ and $K_{I I}$, were calculated according to a procedure described elsewhere $[22,27]$. For each specimen and oxidation time, two FE runs were performed: one where the TGO thickness was derived from the $\mathrm{Al}_{2} \mathrm{O}_{3}$ curve in Fig. 7 and one where the total TGO thickness was taken into account.

The results of the FE simulations are shown in Fig. 11: the stress intensity 
factors, $K_{I}$ and $K_{I I}$, are shown as function of the horizontal crack length. The rather small differences in Young's modulus and CTE between the specimens did not yield any significant difference in stress intensity factors for the $\mathrm{Al}_{2} \mathrm{O}_{3}$ based TGO thickness where the TGO thickness essentially is the same for both HX and H230, as seen in Fig. 11 a) and b). It is clear that differences in mechanical properties of the bond coat and substrate cannot explain the difference in life between the HX and H230 specimens.

TGO thickness based on the total oxide thickness did give a difference in stress intensity factors. The larger TGO thickness for the HX specimens gives a slightly lower $K_{I}$ early during crack growth, but a markedly larger $K_{I I}$ during intermediate and late stages of crack growth, as seen in Fig. 11 c) and d) for $500 \mathrm{~h}$ and $1000 \mathrm{~h}$ respectively.

While the thicker TGO in the HX specimens gave a larger $K_{I I}$, the influence of the thicker TGO may also be the non-alumina oxides' higher growth stresses and tendency for cracking. The Cr- and Ni-rich oxides, often found in clusters, crack easily and their role as crack nucleation sites, and their function as assisting the coalescence of microcracks, have been pointed out by, for example, Chen et al. [28]. A cracked oxide cluster is shown in Fig. 12 where the arrows mark the cracks. Such cracked chromia-spinel-NiO-rich clusters were found both in the HX and H230 specimens, but the larger amount of such oxide clusters indicated by the faster total TGO growth rate for the HX specimens, see Fig. 7, may have contributed to the shorter life.

\section{Conclusions}

Two TBC systems with different substrate materials, Hastelloy $\mathrm{X}$ and Haynes 230, were thermally cycled until failure. The difference in thermal fatigue life was found to be almost a factor 2. Fractography revealed no differences in the fracture behaviour of the two TBC systems: the fracture occurred largely in the $\mathrm{TGO} / \mathrm{TC}$ interface, $34 \%$, and between splats in the TC, $60 \%$.

The oxides on the fracture surfaces contained Mn and small amounts of Fe from the substrate, but otherwise none of the substrate elements appeared to form oxides, even though EDS measurements on cross-sections revealed the interdiffusion of Mo and $\mathrm{W}$ to occur rather readily.

The $\mathrm{Al}_{2} \mathrm{O}_{3}$ growth kinetics was essentially the same for the two TBC systems, however, the total TGO growth rate (also including the growth of chromia, mixed-element-spinels and $\mathrm{NiO}$ ), was substantially faster for the 
TBC system with the Hastelloy X substrate. Al depletion in the bond coat also occurred faster for that TBC system. The two TBC systems were found to fail at essentially the same total TGO thickness. At the time of failure, the bond coat of both TBC systems had been depleted of Al.

Nanoindentation data, and a Thermo-Calc based estimation of the coefficient of thermal expansion, were used as input for a finite element simulation of crack growth in the TGO/TC interface. The difference in Young's modulus and coefficient of thermal expansion between the TBC systems was small and, consequently, the calculated stress intensity factors were similar for both TBC systems. Differences in the mechanical properties of the coating and substrate do not explain the difference in fatigue life.

The causes for the shorter life of the TBC deposited on Hastelloy X are concluded to be: 1) the more pronounced interdiffusion for that TBC system 2) the faster $\mathrm{Al}$ depletion and 3) the higher total TGO growth rate. Large bulky clusters of chromia, spinels and $\mathrm{NiO}$ may act as crack nucleation sites, assist crack coalescence and introduce non-negligible growth stresses in the $\mathrm{BC} / \mathrm{TC}$ interface, thereby shortening the life of TBCs. This finding stresses the importance of establishing the growth kinetics, not only of alumina, but for all types of oxides growing in the bond coat/top coat interface.

\section{Acknowledgement}

This research has been funded by the Swedish Energy Agency, Siemens Industrial Turbomachinery AB, GKN Aerospace Engine Systems, and the Royal Institute of Technology through the Swedish research programme TURBO POWER, the support of which is gratefully acknowledged. E.B. acknowledges the support from the Swedish Government Strategic Research Area Grant in Materials Science (SFO Mat-LiU) on Advanced Functional Materials. Professor Sören Sjöström at Linköping University is also gratefully acknowledged for his contribution to this paper.

\section{References}

[1] X. Zhao, P. Xiao, Mater. Sci. Forum 606 (2009) 1-26.

[2] J. DeMasi-Marcin, D. Gupta, Surf. Coat. Technol. 68-69 (1994) 1-9.

[3] H. Evans, M. Taylor, Proc. IMechE 220 (2006) 1-10. 
[4] G. Goward, Surf. Coat. Technol. 108-109 (1998) 73-79.

[5] M. Pomeroy, Mater. Des. 26 (2005) 223-231.

[6] R. Vassen, A. Stuke, D. Stöver, J. Therm. Spray Technol. 18 (2009) $181-186$.

[7] R. Eriksson, H. Brodin, S. Johansson, L. Östergren, X.-H. Li, Fractographic and microstructural study of isothermally and cyclically heat treated thermal barrier coatings, Surf. Coat. Technol., 2012.

[8] A. Rabiei, A. Evans, Acta Mater. 48 (2000) 3963-3976.

[9] R. Eriksson, H. Brodin, S. Johansson, L. Östergren, X.-H. Li, Surf. Coat. Technol. 205 (2011) 5422-5429.

[10] R. Vassen, F. Cernushi, G. Rizzi, A. Scrivani, N. Markocsan, L. Östergren, A. Kloosterman, R. Mevrel, J. Feist, J. Nicholls, Adv. Eng. Mater. 10 (2008) 907-921.

[11] S. Sjöström, H. Brodin, in: D. Zhu, H.-T. Lin, S. Mathur, T. Ohji (Eds.), Advanced Ceramic Coatings and Interfaces V, volume 31 of $\mathrm{Ce}$ ramic Engineering and Science Proceedings, John Wiley \& Sons, Inc., Hoboken, NJ, USA, 2010.

[12] H. Brodin, Failure of thermal barrier coatings under thermal and mechanical fatigue loading: Microstructural observations and modelling aspects, Ph.D. thesis, Linköpings universitet, 2004.

[13] D. Naumenko, V. Shemet, L. Singheiser, W. Quadakkers, J. Mater. Sci. 44 (2009) 1687-1703.

[14] W. Chen, X. Wu, B. Marple, P. Patnaik, Surf. Coat. Technol. 197 (2005) $109-115$.

[15] R. Wu, K. Kawagishi, H. Harada, R. Reed, Acta Mater. 56 (2008) $3622-$ 3629 .

[16] R. Wu, R. Reed, Acta Mater. 56 (2008) 313-323.

[17] U. Schulz, M. Menzebach, C. Leyens, Y. Yang, Surf. Coat. Technol. 146-147 (2001) 117-123. 
[18] L. He, Z. Xu, J. Li, R. Mu, S. He, G. Huang, J. Mater. Sci. Technol. 25 (2009) 799-802.

[19] B. Pint, I. Wright, W. Lee, Y. Zhang, K. Prüssner, K. Alexander, Mater. Sci. Eng., A 245 (1998) 201-211.

[20] R. Eriksson, H. Brodin, S. Johansson., L. Östergren, X.-H. Li, in: Proceedings of the 19th European Conference on Fracture, ECF19.

[21] T. Beck, M. Schweda, L. Singheiser, Proc. Eng. 55 (2013) 191-198.

[22] M. Jinnestrand, Delamination in APS applied thermal barrier coatings: life modelling, Ph.D. thesis, Linköpings universitet, 2004.

[23] K. Yuan, R. Eriksson, R. L. Peng, X.-H. Li, S. Johansson, Y.-D. Wang, Modeling of microstructural evolution and lifetime prediction of MCrAlY coatings on nickel based superalloys during high temperature oxidation, Surf. Coat. Technol. http://dx.doi.org/10.1016/j.surfcoat.2013.05.008, 2013.

[24] H. Echsler, D. Renusch, M. Schütze, Mater. Sci. Technol. 20 (2004) 307-318.

[25] M. Jinnestrand, S. Sjöström, Surf. Coat. Technol. 135 (2001) 188-195.

[26] H. Brodin, R. Eriksson, S. Johansson, S. Sjöström, in: D. Zhu, H.-T. Lin, D. Singh, J. Salem (Eds.), Advanced Ceramic Coatings and Interfaces IV, volume 30 of Ceramic Engineering and Science Proceedings, John Wiley \& Sons, Inc., Hoboken, NJ, USA, 2010, pp. 113-124.

[27] S. Sjöström, H. Brodin, M. Jinnestrand, Thermomechanical fatigue life of a TBC - comparison of computed and measured behaviour of delamination cracks, to be presented at ICF13 Beijing, China, 2013.

[28] W. Chen, X. Wu, B. Marple, P. Patnaik, Surf. Coat. Technol. 201 (2006) 1074-1079. 


\begin{tabular}{lrrrrrrr}
\hline & & \multicolumn{3}{c}{ Bond coat } & \multicolumn{4}{c}{ Substrate } \\
Specimen & Time, $\mathrm{h}$ & $\mathrm{CTE}, \mu \mathrm{m} / \mathrm{m}^{\circ} \mathrm{C}$ & $E, \mathrm{GPa}$ & $\nu$ & $\mathrm{CTE}, \mu \mathrm{m} / \mathrm{m}^{\circ} \mathrm{C}$ & $E, \mathrm{GPa}$ & $\nu$ \\
\hline H230 & 500 & 17.40 & 222 & 0.31 & 16.1 & 236 & 0.29 \\
$\mathrm{H} 230$ & 1000 & 17.22 & 258 & 0.31 & 16.1 & 279 & 0.29 \\
$\mathrm{HX}$ & 500 & 17.51 & 245 & 0.31 & 16.6 & 233 & 0.29 \\
$\mathrm{HX}$ & 1000 & 16.95 & 231 & 0.31 & 16.6 & 237 & 0.29 \\
\hline
\end{tabular}

Table 1: Data used for finite element modelling of crack growth in the TGO/TC interface. 


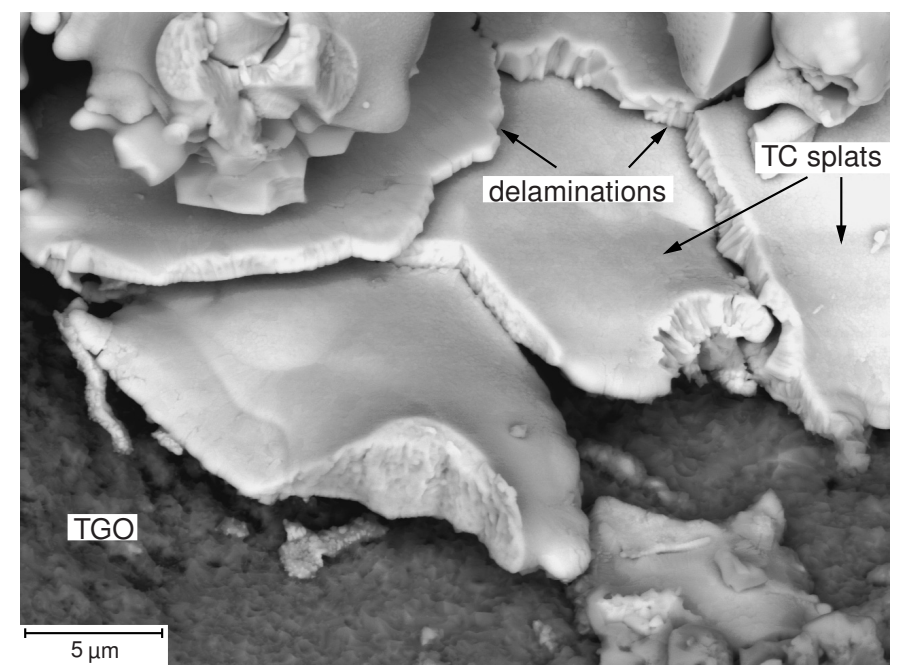

Figure 1: The typical fracture for all studied specimens. Cracking occurs mainly between splats in the top coat and in the TGO/TC interface. 

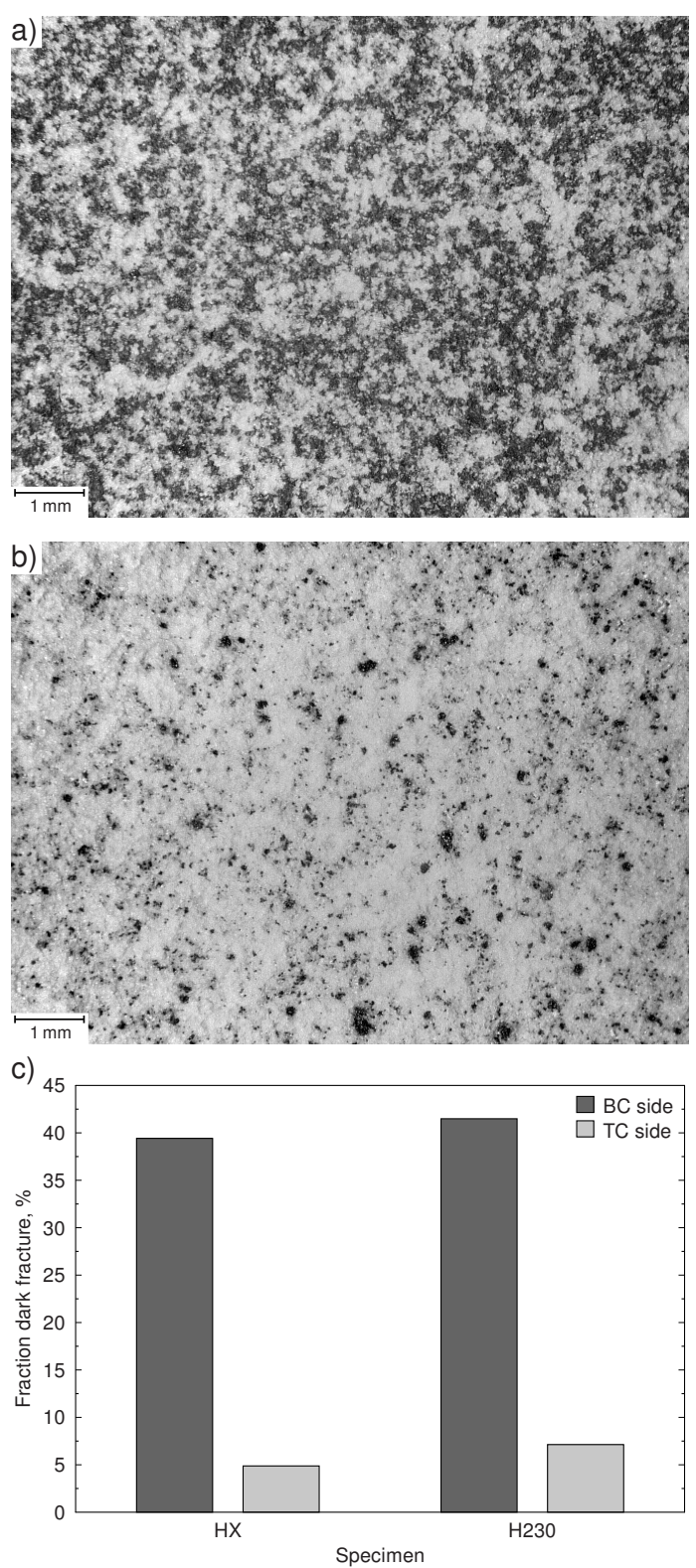

Figure 2: The macroscopic appearance of the fracture surfaces: a) bond coat side, b) top coat side; and c) the fraction of dark fracture on the fracture surfaces. 

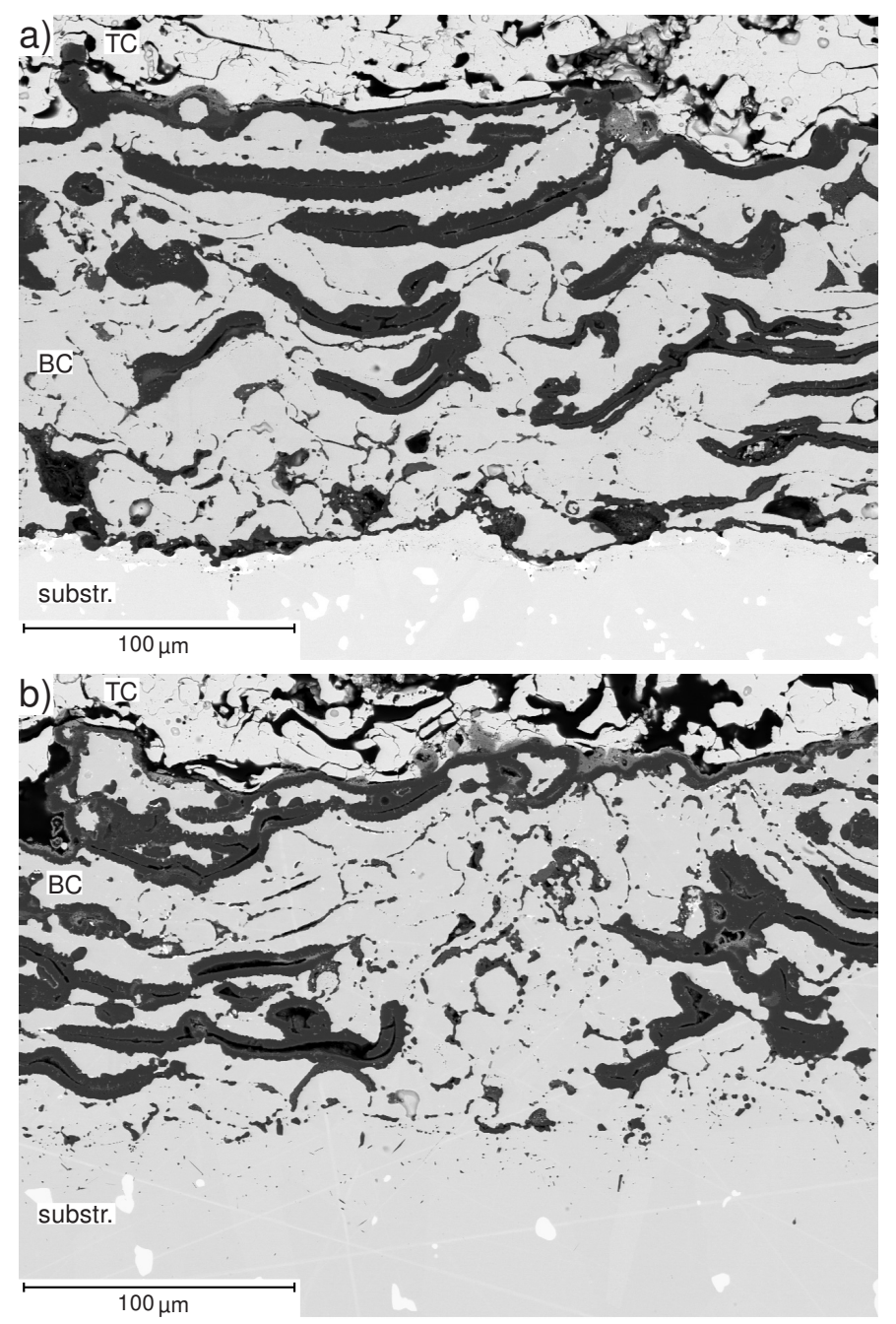

Figure 3: Oxidation of the bond coats after $500 \mathrm{~h}$ at $1100{ }^{\circ} \mathrm{C}$. Cross-sections of: a) the H230 specimen, b) the HX specimen. 

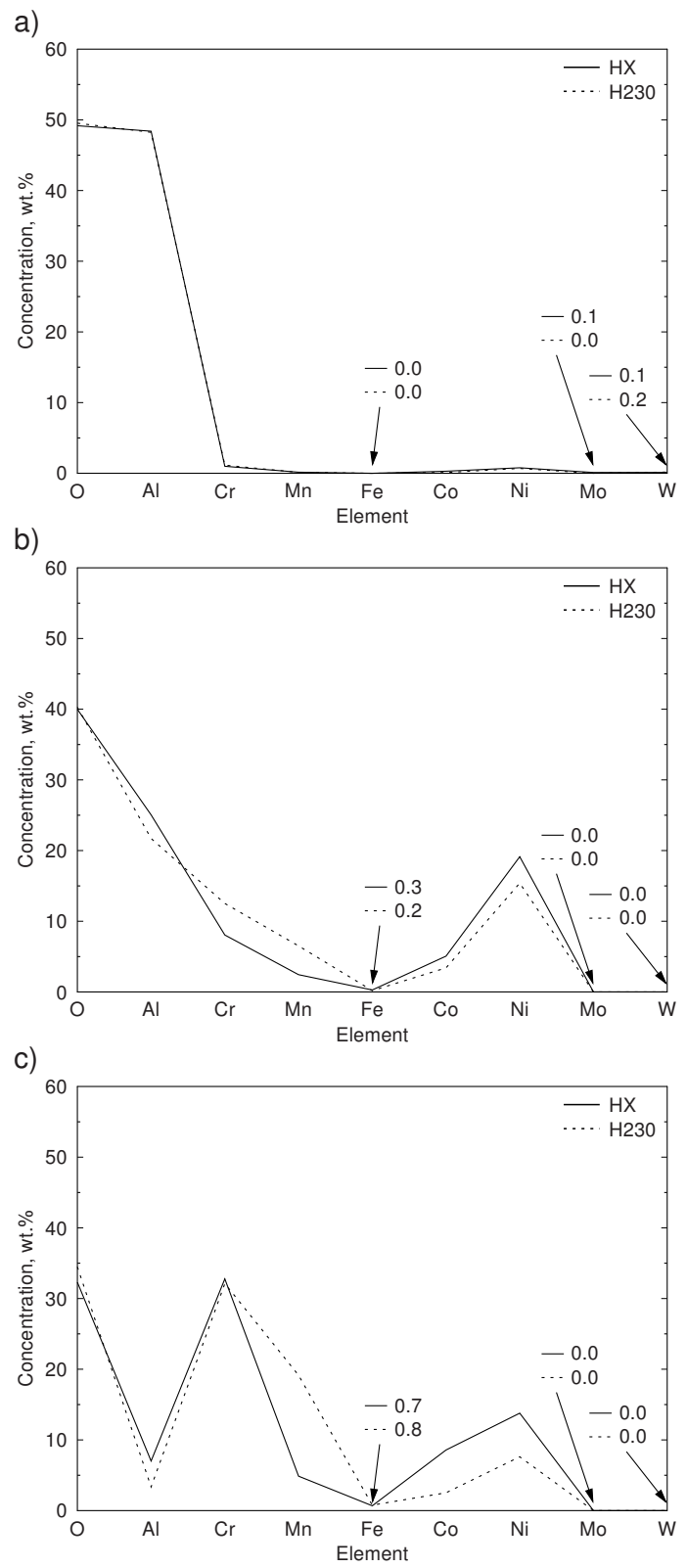

Figure 4: The composition of the oxides on the fracture surfaces divided by oxide type/morphology: a) alumina b) granular oxides c) blocky oxide morphology. The HX specimen failed at 565 cycles and the H230 specimen failed at 1070 cycles. 


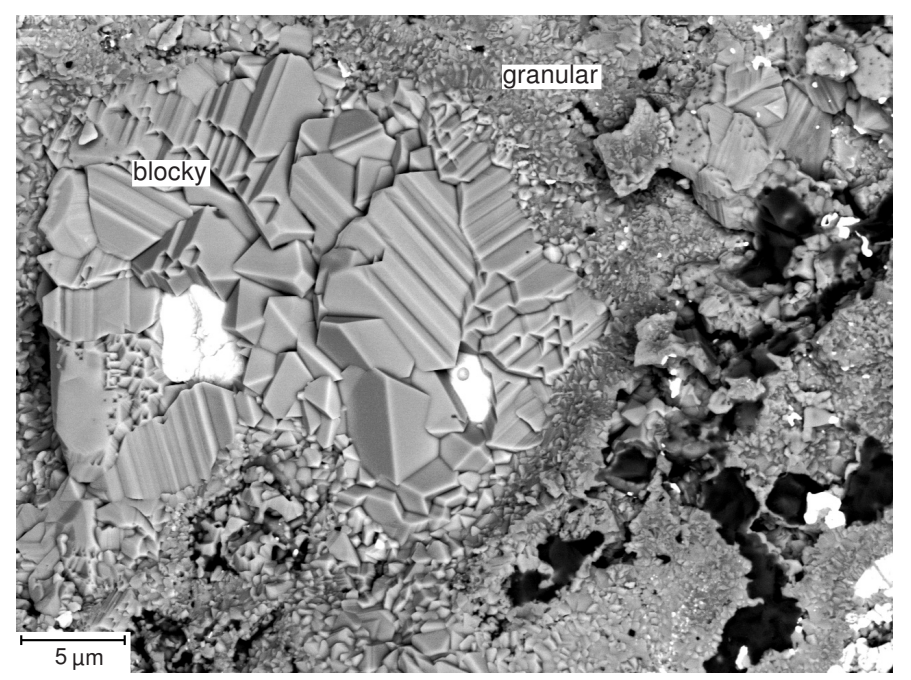

Figure 5: Overview of oxide morphology: blocky and granular morphology. 

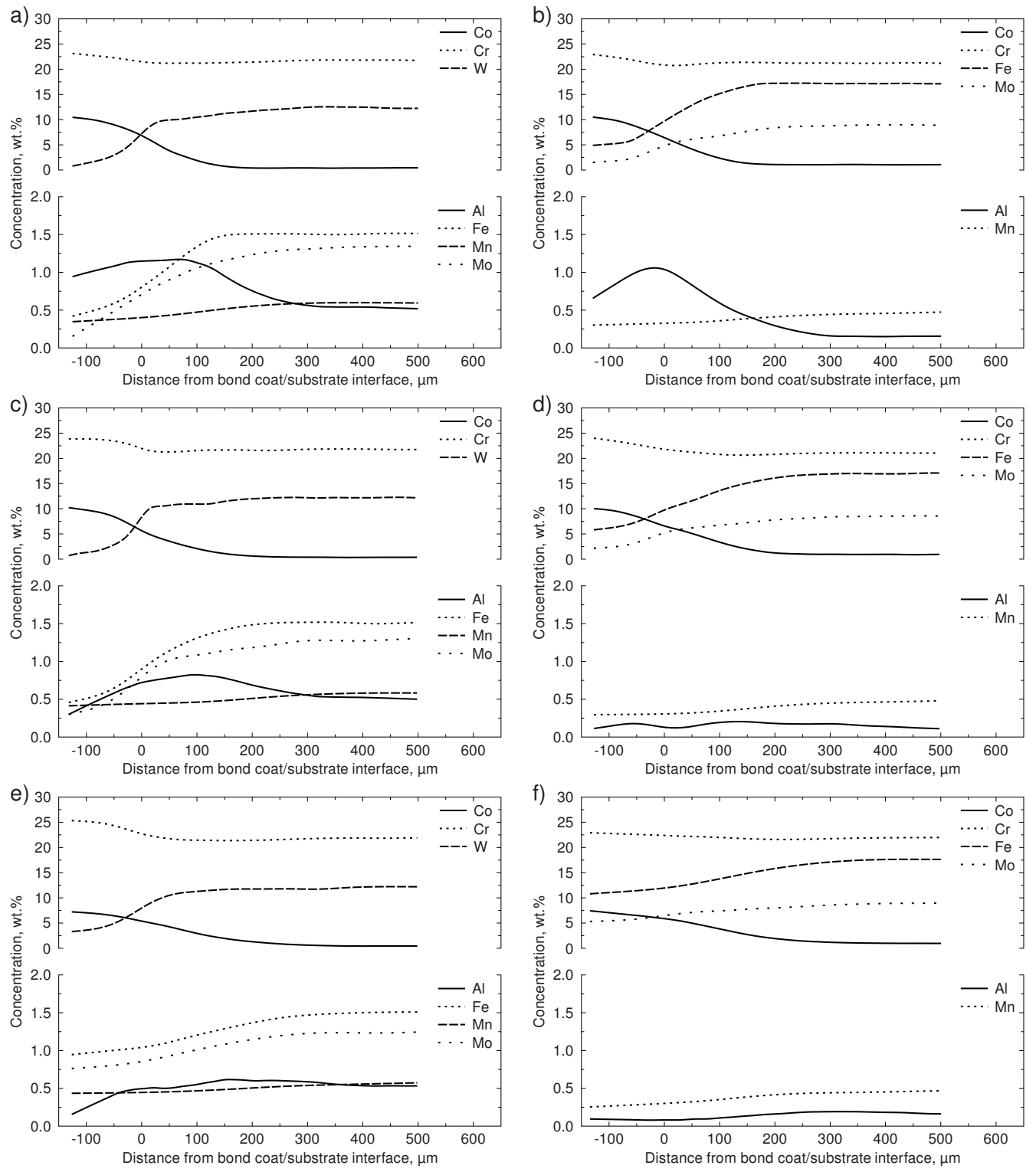

Figure 6: The effect of interdiffusion and oxidation on coating composition. EDS results from cross-sections of specimens oxidised at $1100{ }^{\circ} \mathrm{C}$; negative distance is in the coating. a) H230 oxidised $300 \mathrm{~h}, \mathrm{~b}$ ) HX oxidised $300 \mathrm{~h}, \mathrm{c}$ ) H230 oxidised 500 h, d) HX oxidised 500 h, e) H230 oxidised 1000 h, f) HX oxidised 1000 h. 


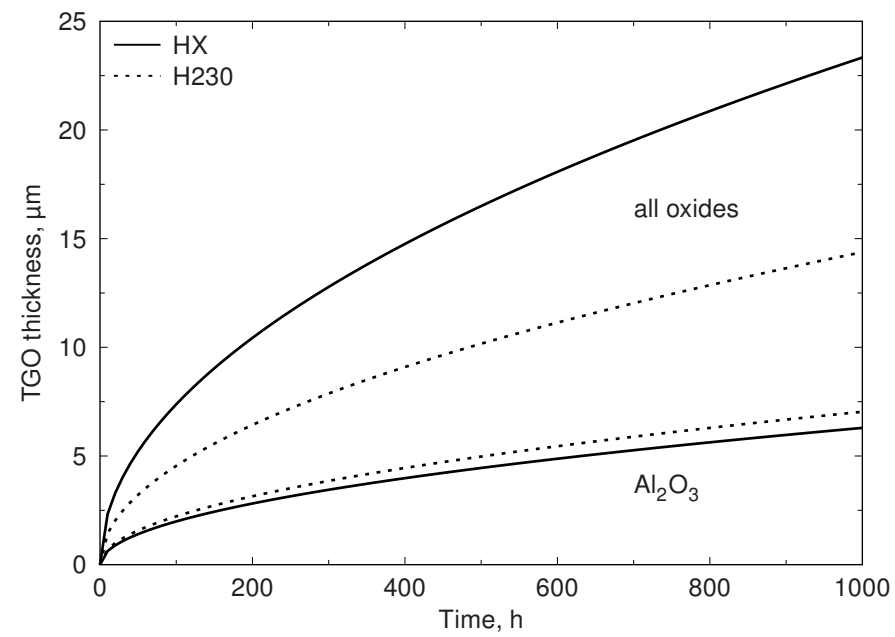

Figure 7: Interface TGO thickness for $\mathrm{Al}_{2} \mathrm{O}_{3}$ and for all kinds of oxides. The curves shown are parabolic oxidation curves established from experimental data. 


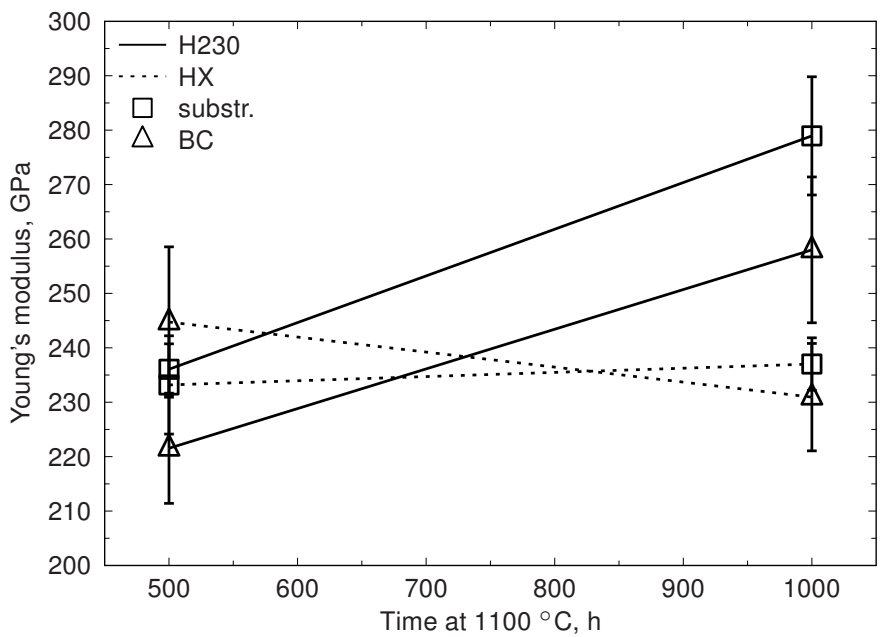

Figure 8: Variation in Young's modulus with oxidation time in the bond coat and the substrate; established by nanoindentation. 


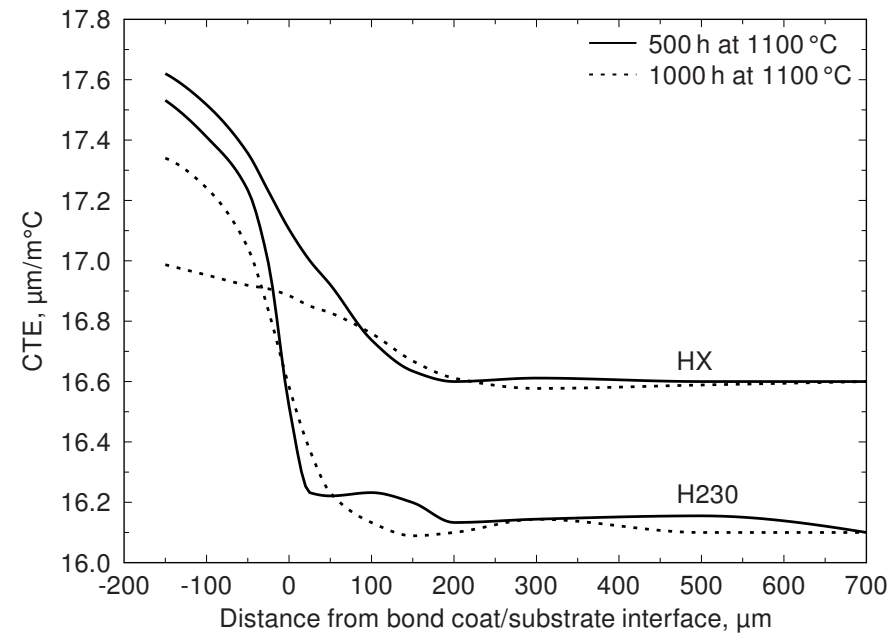

Figure 9: CTE variation through the thickness of the coating and in the substrate; estimations from Thermo-Calc. Negative distance is in the coating. 


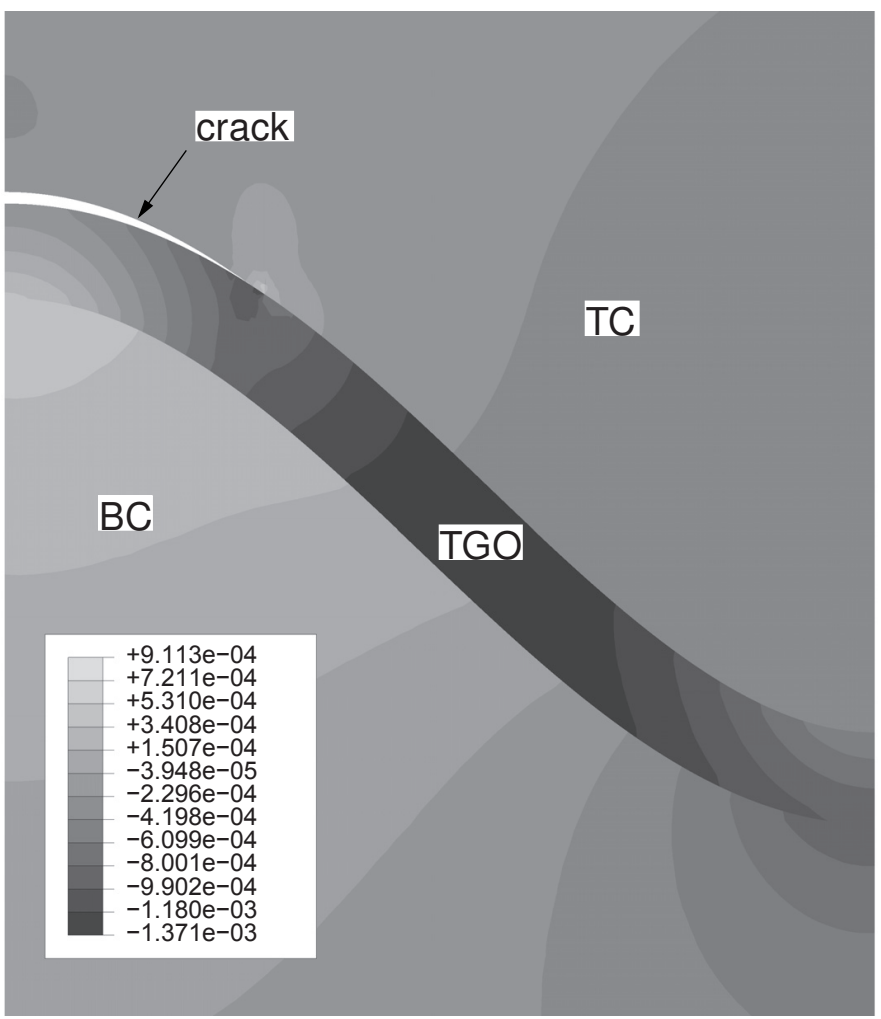

Figure 10: Finite element crack modelling. The crack was modelled to grow in the $\mathrm{TGO} / \mathrm{TC}$ interface from a peak to a valley position. 
a)

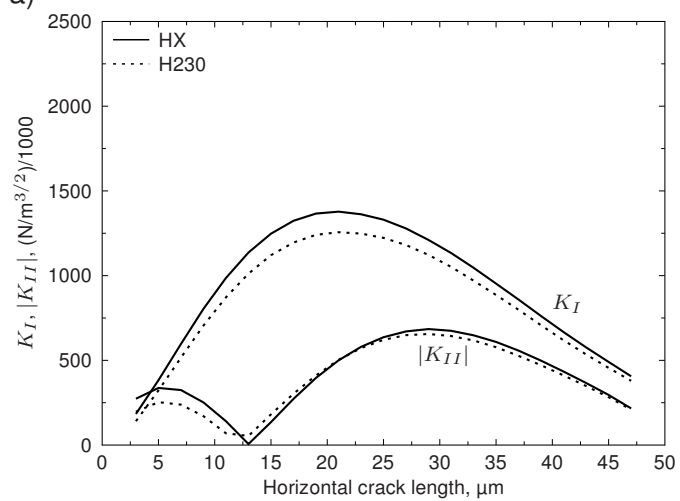

c)

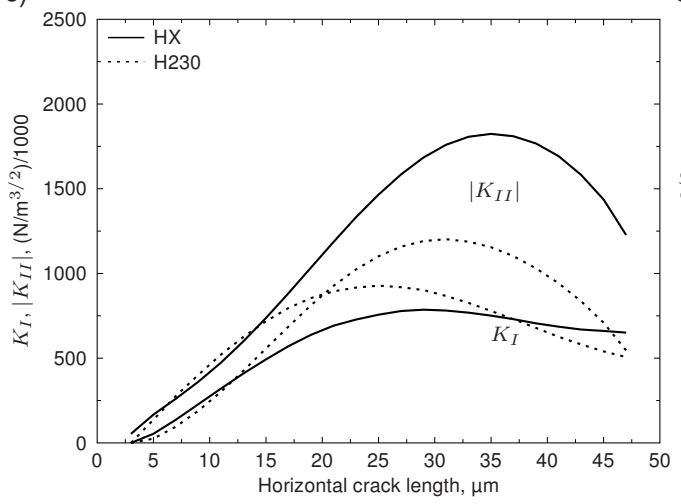

b)

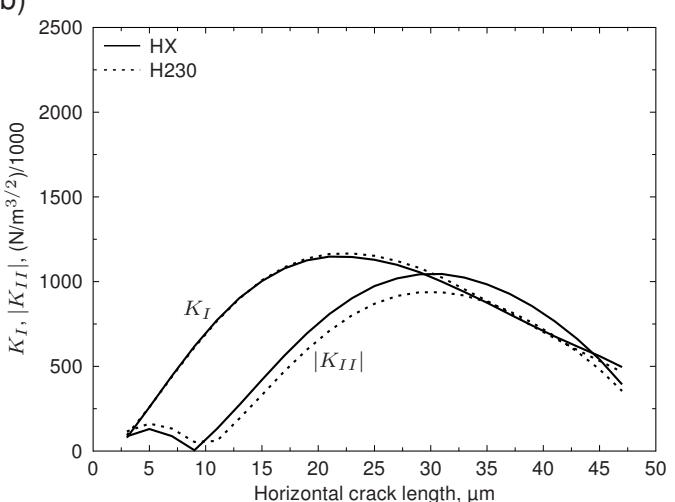

d)

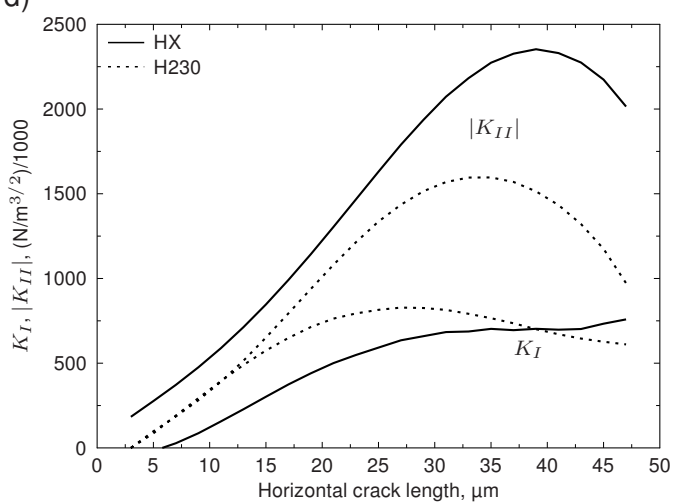

Figure 11: Stress intensity factors, $K_{I}$ and $K_{I I}$, for a crack growing in the TGO/TC interface. Simulation corresponding to: a) $500 \mathrm{~h} \mathrm{Al}_{2} \mathrm{O}_{3}$-based TGO thickness, b) $1000 \mathrm{~h}$ $\mathrm{Al}_{2} \mathrm{O}_{3}$-based TGO thickness, c) $500 \mathrm{~h}$ TGO thickness based on all oxides, d) $1000 \mathrm{~h}$ TGO thickness based on all oxides. 


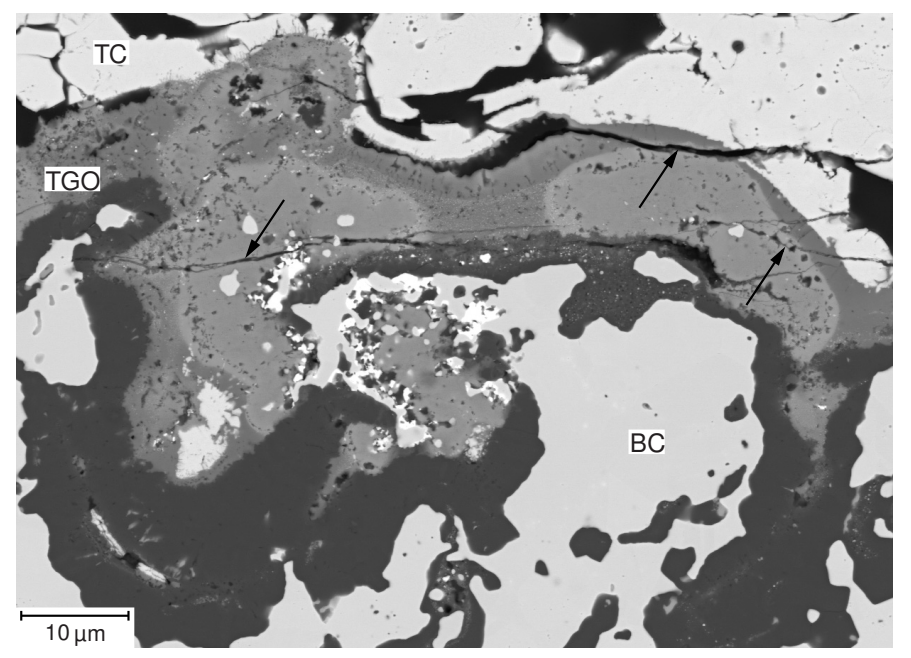

Figure 12: Bulky oxide cluster containing $\mathrm{Cr}$ - and Ni-rich oxides. The arrows mark where the oxide cluster has cracked. 